\title{
EFFECTS OF LOW TESTOSTERONE LEVELS AND OF ADRENAL ANDROGENS ON GROWTH OF PROSTATE TUMOR MODELS IN NUDE MICE
}

\author{
W. M. van Weerden, ${ }^{1 *}$ G. J. van Steenbrugge, ${ }^{1}$ A. van Kreuningen, ${ }^{1}$ E. P. C. M. Moerings, ${ }^{2}$ \\ F. H. DE JONG ${ }^{1}$ and F. H. SCHRÖDER ${ }^{1}$ \\ Departments of 'Urology and ${ }^{2}$ Biochemistry II, Erasmus University, Rotterdam, The Netherlands
}

\begin{abstract}
Summary-Two transplantable, androgen dependent prostate tumor models of human origin, PC-82 and PC-EW, were used to study the effect of low androgen levels and adrenal androgens on prostate tumor cell proliferation. Tumor load of the PC-82 and PC-EW tumors could be maintained constant when plasma testosterone levels were 0.8 and $0.9 \mathrm{nmol} / \mathrm{l}$, respectively, corresponding with an intratissue $5 \alpha$-dihydrotestosterone level of 3-4 pmol/g tissue. This critical androgen level for prostate tumor growth stimulation amounted to 2-3 times the castration level and proved to be similar for both tumor models. Relatively high levels of androstenedione resulted in physiological levels of plasma testosterone causing androgen concentrations in PC-82 tumor tissue exceeding the critical level for tumor growth. These results indicate that submaximal suppression of androgens can stop tumor growth in these prostate tumor models.
\end{abstract}

\section{INTRODUCTION}

Endocrine treatment of prostate cancer patients alone, whatever therapy regimen used, cannot anticipate the relapse phenomenon which always follows the initial response of the tumor to hormonal therapy [1]. It has been questioned whether this transient response to hormonal treatment results from a selective outgrowth of (pre-existing) androgen independent clones of cells $[2,3]$ or is due to an insufficient ablation of androgens $[4,5]$. In men, androgens of adrenal origin, remaining in circulation after castration, may compensate for the castration-induced decline in intraprostatic androgen concentration in part [6]. Many studies, both experimental and clinical, have been conducted in an attempt to reveal whether a more complete androgen ablation than obtained by castration alone, might yield a more favorable result in the treatment of prostatic cancer. To date, there is no definite answer to this question.

In order to study this point in more detail, two androgen dependent prostate tumor models of human origin, PC-82 and PC-EW, were used to investigate the relationship between growth activity of prostatic carcinoma tissue and peripheral and tissue testosterone (T) and $5 \alpha$ -

Proceedings of the 2nd International EORTC Symposium on "Hormonal Manipulation of Cancer: Peptides. Growth Factors and New (Anti-)Steroidal Agents", Rotterdam, The Netherlands, 9-11 April 1990.

*To whom correspondence should be addressed. dihydrotestosterone (DHT) concentrations. In addition, the role of the adrenal androgens androstenedione (A) and dehydroepiandrosterone (DHEA) in prostate tumor growth stimulation was studied.

\section{EXPERIMENTAL}

\section{Tumor model characteristics}

Both tumors used in this study, PC-82 and PC-EW, are of human origin and serially transplantable in nude mice. The PC- 82 tumor model is derived from a primary, moderately differentiated adenocarcinoma of the prostate $[7,8]$. The PC-EW tumor originates from a lymph node metastasis and is composed of poorly and moderately differentiated carcinoma [9]. These tumor models share many of the properties seen in clinical prostate cancer. Although tumor take $(85 \%)$ and tumor doubling time (18 days) are similar for both tumors, the PC-EW tumor regresses much faster after androgen withdrawal than the PC-82 tumor; tumor halftime being 8 and 17 days, respectively.

\section{Manipulation of plasma testosterone levels in} mice

Female or castrated male nude mice of the $\mathrm{Balb} / \mathrm{c}$ background were routinely substituted with $\mathrm{T}$ by subcutaneous implantation of Silastic capsules $(0.4 \mathrm{~cm})$ filled with the crystalline steroid [10]. Because the release of $T$ from these implants was too high to obtain relatively low 
levels of $\mathrm{T}$, in the low dose resubstitution studies Silastic implants $(0.6 \mathrm{~cm})$ were filled with either cholesterol $(0 \% \mathrm{~T})$ or with cholesterol mixed with different amounts of $\mathrm{T}(5,10,25$ and $100 \% \mathrm{~T}$ implants), resulting in various plasma $\mathrm{T}$ levels.

\section{Experimental protocol}

To study the effect of various levels of androgen on prostate tumor growth without influencing tumor take, mice were transplanted with small fragments of tumor tissue and simultaneously substituted with a standard dose of $\mathrm{T}$ $(0.4 \mathrm{~cm}$ length; resulting peripheral $\mathrm{T}$ level: $10 \mathrm{nmol} / \mathrm{l})$ to assure an optimal tumor take and tumor growth. When tumors were in the exponential phase of growth, implants were removed for a short period of time to deplete the tumor tissue of androgens. Because of the difference in regression rate, depletion periods of 12 and 5 days were chosen for the PC-82 and PC-EW tumors, respectively. Subsequently, mice were resubstituted with implants containing various doses of T (Fig. 1). Tumor volume changes were followed weekly by caliper measurements. Tumor volume was calculated according to the formula

$$
V=\pi / 6\left(d_{1} \times d_{2}\right)^{3 / 2},
$$

in which $d_{1}$ and $d_{2}$ are two perpendicular tumor diameters. After 28 days mice were sacrificed and plasma and tumor tissue were collected.

\section{Substitution with adrenal androgens}

The ability of adrenal androgens to support prostate tumor growth was studied by implanting mice with $\mathrm{A}$ and DHEA packed in Silastic tubings. As the adrenal glands of mice do not produce androgens (results not shown), endogenous synthesis of adrenal androgens cannot interfere with adrenal androgen substitution in this model. Mice were treated according to the same protocol followed for the $\mathrm{T}$ supplementation experiments (Fig. 1).

Hormone estimations in plasma and tumor tissue

$\mathrm{T}$ and DHT levels in tumor tissue were estimated in whole tissue homogenates after separ-

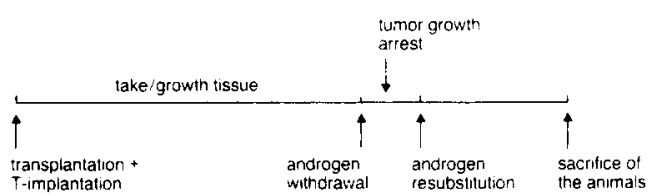

Fig. 1. Protocol for the experiments with PC-82 and PC-EW grown under various androgen levels. ation of the androgens on silica columns as described by Hämäläinen et al. [11]. Plasma androgen content and separated androgen fractions from the tissue homogenates were analyzed by a radioimmunoassay [12]. This procedure has been described in more detail elsewhere [13].

\section{Statistical procedure}

All data are expressed as the mean \pm standard error of the mean (SEM) with the number of animals in parentheses. All group differences were statistically analyzed using the Student $t$-test and were considered significant when $P<0.05$.

\section{RESULTS}

\section{Plasma and intratissue levels of androgen}

Substitution of female or castrated male mice with various doses of $\mathrm{T}$ resulted in plasma levels ranging from 0 to $20 \mathrm{nmol} / 1$ (Table 1). These levels, as well as the growth response of the tumors, did not differ significantly between implanted females and castrated males. A significant correlation was observed between plasma $\mathrm{T}$ and intratumor DHT concentration for both tumor models (PC-82-r $=0.87$, $n=34, P<0.001$; PC-EW- $r=0.69, n=23$, $P<0.05$ ). In all substituted groups PC-EW tumor tissue had a significantly lower DHT content than PC-82 tumor tissue, whereas a similar castrate level of DHT $(0 \% \mathrm{~T})$ was found in both tumors.

\section{Threshold level for tumor growth stimulation}

A significant dose-response relationship between intratumor DHT concentration and tumor growth was observed in both the PC-82 and PC-EW tumor models $(r=0.88, n=39$, $P<0.001$; and $r=0.91, n=17, P<0.001$, respectively). Tumor growth in 10 and $25 \% \mathrm{~T}$ substituted mice was significantly retarded compared to the tumor growth observed in the $100 \% \mathrm{~T}$ substituted mice. Maintenance of the

Table 1. Plasma $T$ levels in mice bearing the PC -82 or PC-EW tumor at the end of the experiment (28 days)

\begin{tabular}{cc}
\hline $\begin{array}{c}\text { Proportion of T } \\
\text { in implant }(\% \mathrm{~T})\end{array}$ & $\begin{array}{c}\text { Plasma level } \\
\text { of } \mathrm{T}(\mathrm{nmol} / \mathrm{l})\end{array}$ \\
\hline 0 & $0.1 \pm 0.03(18)$ \\
5 & $0.6 \pm 0.2(12)$ \\
10 & $1.3 \pm 0.3(17)$ \\
25 & $4.5 \pm 1.0 \quad(4)$ \\
100 & $15.6 \pm 1.3 \quad(8)$ \\
\hline
\end{tabular}

Plasma $\mathrm{T}$ levels were significantly different between all groups $(P<0.05)$. 


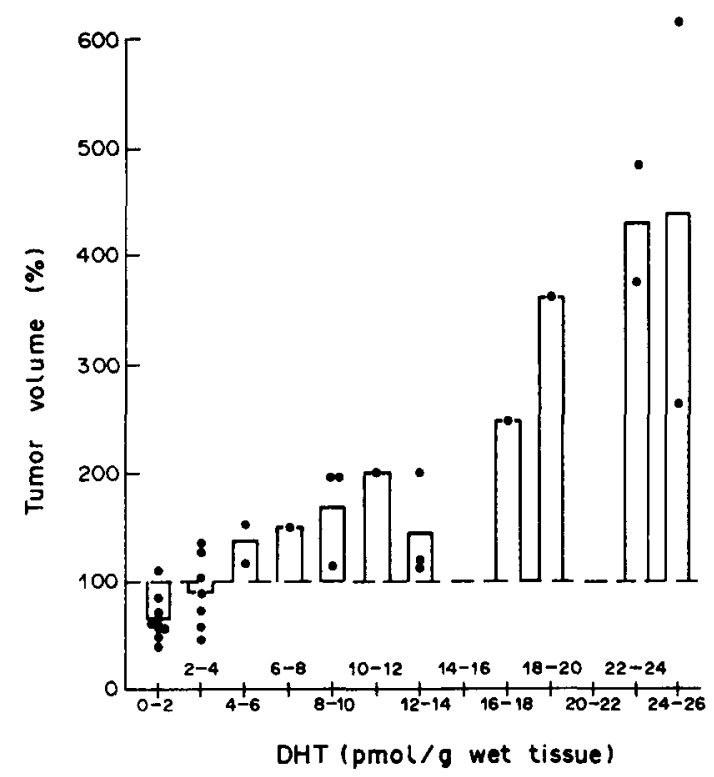

Fig. 2. Relationship between intratissue DHT content and PC-82 tumor growth.

PC-82 tumor was achieved at a plasma $T$ level of $0.8 \pm 0.8 \mathrm{nmol} / 1$, corresponding with intratissue $\mathrm{T}$ and DHT levels of $6-10$ and 3-4 pmol/g tissue (Fig. 2). Stabilization of the PC-EW tumor volume was observed at similar $T$ levels $(0.9 \pm 0.9 \mathrm{nmol} / \mathrm{l})$ resulting in intratumor T and DHT concentrations of 5-9 and 2-3 pmol/g tissue (Fig. 3). Both tumors showed a decline in tumor burden in $0 \% \mathrm{~T}$ substituted mice $(0.1-0.2 \mathrm{nmol} / \mathrm{l})$, which was comparable to the regression normally seen in castrated animals. DHT threshold levels for growth stimulation of both PC-82 and PC-EW tumors were approx. $3 \mathrm{pmol} / \mathrm{g}$ tissue.

PC-82 tumor growth with adrenal androgen substitution

Supplementing mice with DHEA (peripheral levels: $9.2 \pm 1.7 \mathrm{nmol} / \mathrm{l}$ ) did not result in any PC-82 tumor growth stimulation. The tumor regression observed in these mice was equal to that observed in the $0 \% \mathrm{~T}$ implanted mice (Table 2). Although plasma levels of $T$ in

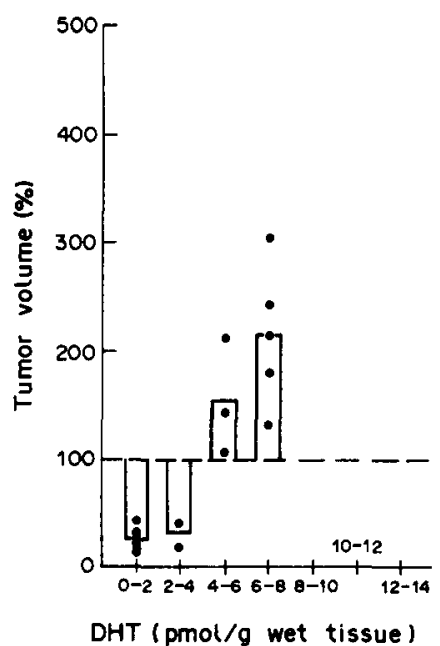

Fig. 3. Relationship between intratissue DHT content and PC-EW tumor growth.

DHEA substituted mice were above the castration level $(1.2 \pm 0.2 \mathrm{nmol} / 1)$, intratissue androgen levels were not significantly different from those of castrated animals (data not shown). Substitution of A caused plasma $T$ levels of $10.7 \pm 1.6 \mathrm{nmol} / 1$ and accordingly induced an increase in PC-82 tumor volume which was significantly less than that observed in the $100 \% \mathrm{~T}$ implanted mice (Table 2).

\section{DISCUSSION}

After castration of prostate cancer patients plasma levels of androgens decrease markedly, whereas relatively high levels of $\mathrm{T}$ and DHT remain present in the prostate [14]. Obviously, these levels originate from androgens secreted by the adrenal glands and it is well-known that prostatic tissue is capable of metabolizing adrenal androgens into T and DHT [15]. In this study the relevance of these remaining levels of androgens for growth stimulation of human prostate tumor tissue was investigated.

From the experiments presented here, it became evident that growth of PC-82 and PC-EW prostate tumor tissue could be stimulated when

Table 2. PC-82 tumor growth and plasma levels of DHEA, $A$ and $T$ in female nude mice supplemented with DHEA, A, 0 and $100 \% \mathrm{~T}$

\begin{tabular}{lcccc}
\hline & & \multicolumn{2}{c}{ Plasma level $(\mathrm{nmol} / 1)$} & \multirow{2}{*}{$\begin{array}{c}\text { Tumor volume } \\
\left(\mathrm{mm}^{3}\right)\end{array}$} \\
\cline { 3 - 4 } Androgen & DHEA & $\mathrm{A}$ & $\mathrm{T}$ & \\
\hline $0 \% \mathrm{~T}$ & $0.7 \pm 0.2(5)$ & $0.9 \pm 0.3(5)$ & $0.3 \pm 0.1(9)$ & $60 \pm 4(11)$ \\
DHEA & $9.2 \pm 1.7(5)^{\mathrm{a}}$ & $\mathrm{ND}$ & $1.2 \pm 0.2(10)^{\mathrm{a}}$ & $71 \pm 4(11)$ \\
A & ND & $13.5 \pm 1.3(5)^{\mathrm{a}}$ & $11.9 \pm 1.4(7)^{\mathrm{b}}$ & $217 \pm 15(8)^{\mathrm{b}}$ \\
$100 \% \mathrm{~T}$ & $\mathrm{ND}$ & $\mathrm{ND}$ & $17.6 \pm 2.1(3)$ & $362 \pm 44(4)$ \\
\hline
\end{tabular}

Mice were sacrificed at the end of the experiment (28 days). ND not detected.

aSignificantly different from $0 \% \mathrm{~T}(P<0.05)$.

${ }^{b}$ Significantly different from $100 \% \mathrm{~T}(P<0.05)$ 
intratissue DHT exceeded approx. $3 \mathrm{pmol} / \mathrm{g}$ tissue. This intratumor level of DHT, which is 2-3 times the level found in $0 \% \mathrm{~T}$ implanted or castrated mice, can be regarded as a threshold level for tumor growth stimulation [13], although, lower levels of androgen did result in a maximal reduction of tumor burden.

The response of the PC-EW tumor to androgen depletion differs from that of the PC-82 tumor, as PC-EW regresses much faster. In addition, PC-EW has considerably lower intratissue levels of DHT as compared to the PC-82 tumor model (Figs 2 and 3). Remarkably, the critical level of intratissue DHT for tumor growth is similar for both tumor models. The question remains, however, whether all prostatic carcinomas do have a similar cut-off point for minimal stimulating androgen levels. The adrenal androgen DHEA could not prevent regression nor could it activate growth in both tumor models. In contrast, A induced a marked increase in plasma $T$ levels, resulting in high levels of intratissue $\mathrm{T}$ and DHT levels in the PC-82 tumor. These levels, which exceeded the threshold level for growth stimulation, caused the PC-82 tumor to grow accordingly (Table 2). It should be mentioned, however, that these plasma levels of $\mathrm{A}$ were above the levels normally found in castrated men, as in a group of patients treated with an LHRH agonist A levels of 4-5 nmol/1 were observed (own clinical data). Experiments with levels of $\mathrm{A}$ which are more close to the clinical situation are currently being carried out.

After surgical or chemical castration of prostate cancer patients DHT levels in the prostrate remain relatively high: in prostatic tissue of castrated prostate cancer patients average DHT levels of $4 \mathrm{pmol} / \mathrm{g}$ were found $[16,17]$. However, 7 out of the 38 patients had DHT levels $>6.5 \mathrm{pmol} / \mathrm{g}$ tissue, whereas the majority of the patients had DHT levels $<4 \mathrm{pmol} / \mathrm{g}$ [18]. Intraprostatic concentrations of DHT found in a majority of prostate cancer patients after orchiectomy may therefore be considered low enough to prevent prostate tumor growth, whereas in only a few patients DHT levels exceed the level found to be stimulatory for the prostate tumor models PC-82 and PC-EW.

In conclusion, the data presented in this paper indicate that partial androgen withdrawal can stop tumor growth in the prostate tumor models PC-82 and PC-EW. This indicates that total androgen ablation is not needed to prevent growth of these tumors. Relatively high plasma levels of A were found to be stimulatory for PC-82 tumor growth, which implies that adrenal androgens may be involved in clinical prostate cancer.

Acknowledgements - The authors are grateful to Carla Oostveen-van $\mathrm{Hal}$ for determining the plasma androgen levels. The Dutch Cancer Society and the Nijbakker-Morra Foundation are acknowledged for their support (Grant IKR 87.8).

\section{REFERENCES}

1. Schulze H., Isaacs J. T. and Coffey D. S.: A critical review of the concept of total androgen ablation in the treatment of prostate cancer. In Prostate Cancer, Part A: Research, Endocrine Treatment, and Histopathology (Edited by G. P. Murphy ef al.). Liss, New York (1987) pp. $1-19$.

2. Isaacs J. T. and Coffey D. S.: Adaptation versus selection as the mechanism responsible for the relapse of prostatic cancer to androgen ablation therapy as studied in the Dunning R-3327-H adenocarcinoma. Cancer Res. 41 (1981) 5070-5075.

3. Bruchovsky N., Brown E. M., Coppin C. M., Goldenberg S. L., Le Riche J. C., Murray N. C. and Rennie P. S.: The endocrinology and treatment of prostate tumor progression. In Current Concepts and Approaches to the Study of Prostate Cancer (Edited by D. S. Coffey et al.). Liss, New York, Vol. 239 (1987) pp. $347-387$.

4. Labrie F., Luthy I., Veilleux R., Simard J., Belanger A. and Dupont $A$ : New concepts on the androgen sensitivity of prostate cancer. In Prostate Cancer. Part A: Research, Endocrine Treatment, and Histopathology (Edited by G. P. Murphy et al.). Liss, New York (1987) pp. $145-172$.

5. Geller J., Albert J. and Vik A.: Advantages of total androgen blockade in the treatment of advanced prostate cancer. Semin. Oncol. 15 (1988) 53-61.

6. Belanger A., Labrie F. and Dupont A.: Androgen levels in prostatic tissue of patients with carcinoma of the prostate treated with the combined therapy using an LHRH agonist and a pure antiandrogen. Eur. J. Cancer Clin. Oncol. 22 (1986) 742.

7. Hoehn W., Schroeder F. H., Riemann J. F., Joebsis A. C. and Hermanek P.: Human prostatic adenocarcinoma: some characteristics of a serially transplantable line in nude mice (PC-82). Prostate 1 (1980) 95-104.

8. Steenbrugge G. J. van, Groen M.. Romijn J. C. and Schröder F. H.: Biological effects of hormonal treatment regimens on a transplantable human prostatic tumor line (PC-82). J. Urol. 131 (1984) 812-817.

9. Hoehn W., Wagner M., Riemann J. F., Hermanek P., Williams W.. Walther R. and Schrueffer R.: Prostatic adenocarcinoma PC-EW, a new human tumor line transplantable in nude mice. Prostate 5 (1984) 445-452.

10. Steenbrugge G. J. van, Groen M., Jong F. H. de and Schröder F. H.: The use of steroid-containing silastic implants in male nude mice: plasma hormone levels and the effect of implantation on the weights of the ventral prostate and seminal vesicles. Prostate 5 (1984) 639-647.

11. Hämäläinen E. K., Fotsis T. and Adlercreutz H.: Rapid and reliable separation of $5 \alpha$-dihydrotestosterone from testosterone and silica gel microcolumns. Clinica Chim Acta 139 (1984) 173-177.

12. Verjans H. L., Cooke B. A.. Jong F. H. de and Jong C. M. M. de: Evaluation of a radioimmunoassay for testosterone estimation. J. Steroid Biochem. 4 (1973) 665-676. 
13. Weerden W. M. van, Steenbrugge G. J. van, Kreuningen A. van, Moerings E. P. C. M., Jong F. H. de and Schröder F. H.: Assessment of the critical level of androgen for growth response of transplantable human prostatic carcinoma (PC-82) in nude mice. J. Urol. (In press).

14. Geller $J$. and Albert $J$.: Effects of castration compared with total androgen blockage on tissue dihydrotestosterone (DHT) concentration in benign prostatic hyperplasia (BPH). Urol. Res. 15 (1987) 151-153.

15. Harper M. E., Pike A., Peeling W. B. and Griffiths K.: Steroids of adrenal origin metabolized by human pro- static tissue both in vivo and in vitro. J. Endocr. 60 (1974) 117-125.

16. Belanger B., Belanger A., Labrie F., Dupont A., Cusan L. and Monfette G.: Comparison of residual C-19 steroids in plasma and prostatic tissue of human, rat and guinea pig after castration: unique importance of extratesticular androgens in men. J. Steroid Biochem. 32 (1989) 695-698.

17. Geller J. and Candari C. D.: Comparison of dihydrotestosterone levels in prostatic cancer metastases and primary prostate cancer. Prostate 15 (1989) 171-175.

18. Geller J. Personal communication (1989). 